\title{
A Dark Hole in Our Understanding of Marine Ecosystems and Their Services: Perspectives from the Mesopelagic Community
}

\begin{abstract}
Michael A. St. John ${ }^{1 *}$, Angel Borja ${ }^{2}$, Guillem Chust ${ }^{2}$, Michael Heath ${ }^{3}$, Ivo Grigorov ${ }^{1}$, Patrizio Mariani ${ }^{1}$, Adrian P. Martin ${ }^{4}$ and Ricardo S. Santos ${ }^{5,6}$

${ }^{1}$ National Institute of Aquatic Resources, Danish Technical University-Aqua, Charlottenlund, Denmark, ${ }^{2}$ AZTI-Tecnalia, Txatxarramendi Ugartea z/gZ/G, Sukarrieta, Spain, ${ }^{3}$ MASTS Marine Population Modelling Group, Department of Mathematics and Statistics, University of Strathclyde, Glasgow, UK, ${ }^{4}$ National Oceanography Centre, Southampton, UK, ${ }^{5}$ MARE, Department of Oceanography and Fisheries, University of the Azores, Horta, Portugal, ${ }^{6}$ European Parliament, Bruxelles, Belgium
\end{abstract}

OPEN ACCESS

Edited by:

Christos Dimitrios Arvanitidis, Hellenic Centre for Marine Research,

Greece

Reviewed by:

Athanassios C. Tsikliras, Aristotle University of Thessaloniki,

Greece

George Tserpes,

Hellenic Centre for Marine Research (HCMR), Greece

Dag Lorents Aksnes,

University of Bergen, Norway

*Correspondence: Michael A. St. John mstjo@aqua.dtu.dk

Specialty section This article was submitted to Marine Ecosystem Ecology,

a section of the journal Frontiers in Marine Science

Received: 18 January 2016 Accepted: 03 March 2016 Published: 17 March 2016

Citation:

St. John MA, Borja A, Chust G, Heath M, Grigorov I, Mariani $P$, Martin AP and Santos RS (2016) A Dark Hole in Our Understanding of

Marine Ecosystems and Their Services: Perspectives from the

Mesopelagic Community.

Front. Mar. Sci. 3:31

doi: 10.3389/fmars.2016.00031
In the face of increasing anthropogenic pressures acting on the Earth system, urgent actions are needed to guarantee efficient resource management and sustainable development for our growing human population. Our oceans - the largest underexplored component of the Earth system-are potentially home for a large number of new resources, which can directly impact upon food security and the wellbeing of humanity. However, the extraction of these resources has repercussions for biodiversity and the oceans ability to sequester green house gases and thereby climate. In the search for "new resources" to unlock the economic potential of the global oceans, recent observations have identified a large unexploited biomass of mesopelagic fish living in the deep ocean. This biomass has recently been estimated to be 10 billion metric tons, 10 times larger than previous estimates however the real biomass is still in question. If we are able to exploit this community at sustainable levels without impacting upon biodiversity and compromising the oceans' ability to sequester carbon, we can produce more food and potentially many new nutraceutical products. However, to meet the needs of present generations without compromising the needs of future generations, we need to guarantee a sustainable exploitation of these resources. To do so requires a holistic assessment of the community and an understanding of the mechanisms controlling this biomass, its role in the preservation of biodiversity and its influence on climate as well as management tools able to weigh the costs and benefits of exploitation of this community.

Keywords: mesopelagic community, food provision, climate regulation, biodiversity, benefits Risks

\section{INTRODUCTION}

One of the most understudied regions in the world oceans is the twilight zone (200-1000 m depth) which is the domain of the mesopelagic community. Lanternfishes (Myctophiids), which dominate the fish community, are a diverse group comprising around 245 species in 33 genera, distributed globally from polar to equatorial waters, with a maximum body size of $10-15 \mathrm{~cm}$ (Paxton, 1979). Along with an associated community of mainly mesopelagic crustaceans and cephalopods Figure 1 


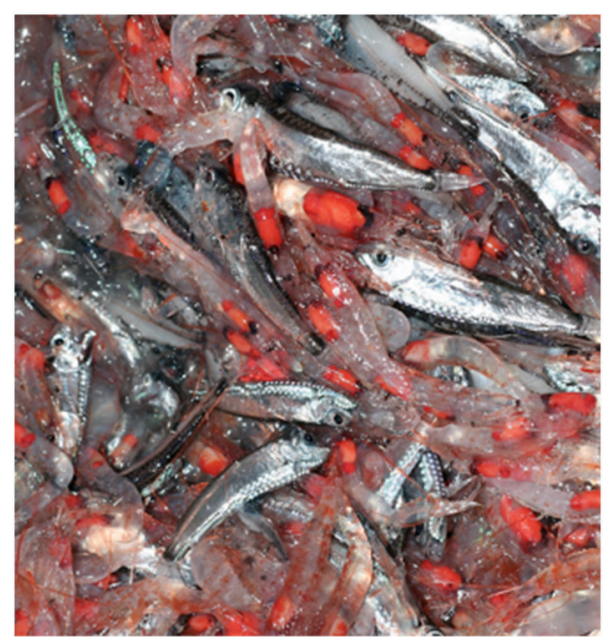

FIGURE 1 | Representative sample of mesopelagic fish including Maurolicus muelleri, Sergestes arcticus, and Benthosema glaciale and plankton e.g., Meganyctiphanes norvegica in the deep scatter layers of the Irminger Sea in November 2013.

(Feagans-Bartow and Sutton, 2014), the community forms distinct acoustic scattering layers at around $500 \mathrm{~m}$ over large expanses of the ocean during day-time, ascending to the upper $150 \mathrm{~m}$ and dispersing at night (Figure 2). This diel migration has been referred to as the "largest daily migration of animals on earth" (Hays, 2003; van Haren and Compton, 2013). The discovery of new species from viruses to large vertebrates is regular in this oceanic zone, supporting estimates of a million undescribed species living in the deep pelagic (Robison, 2009).

Resource strategists have identified the mesopelagic fish and plankton community, living in this twilight zone of the ocean (200-1000 m, depth), as a potential unexploited resource potentially contributing to the long term Blue Growth strategy set by the European Union, i.e., "smart, sustainable and inclusive economic and employment and growth from the oceans, seas and coasts", (e.g., Gjøsæter and Kawaguchi, 1980; FAO, 1997, 1998, 2001; Valinassab et al., 2007). Central to following a Blue Growth strategy for unlocking the potential of seas and oceans is the sustainable exploitation of the new resources provided by marine ecosystems tempered with the preservation of the existing services that the seas and oceans provide.

Despite the potential benefits, harvesting from this community (e.g., mesopelagic fish biomass recent estimates of 10 billion tons although still in question) is problematic and comes with a number of risks. For example, the community plays an integral role in carbon sequestration and thus climate regulation (e.g., Hidaka et al., 2001; Hudson et al., 2014) and is a key resource for higher trophic levels, serving as prey for marine mammals and key fisheries stocks such as tunas, billfish and sharks (e.g., Potier et al., 2007; Brophy et al., 2009) thereby influencing and maintaining biodiversity. Hence, the mesopelagic community potentially impacts upon traditional fisheries and ecotourism as well as climate via the biological carbon pump (Davison et al., 2013). By exploiting

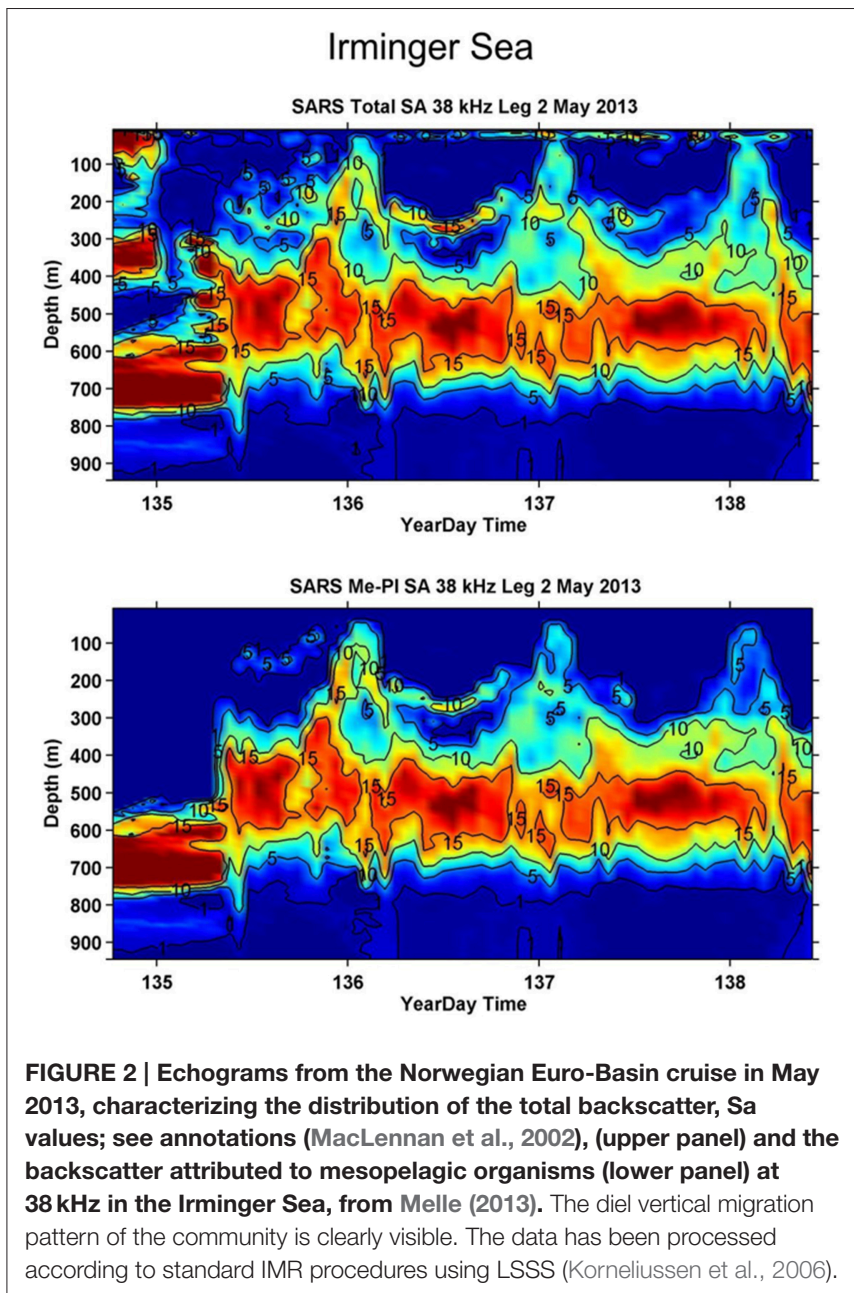

this community, we can potentially produce more food for human consumption and nutraceutical products but there are potentially significant trade-offs related to climate regulation and conservation of biodiversity. Knowledge to assess these trade-offs is presently lacking and it is necessary to develop and apply an ecosystem based management framework for balancing the benefits, risks and trade-offs and to ensure sustainable management of the services that may be provided by the mesopelagic community. With this as the background, here we review some of the potential services, which the mesopelagic community can provide and the implications of exploitation.

\section{FOOD PROVISION}

Food insecurity is a major global issue, with human populations across much of central Africa and southeast Asia facing significant hunger today. Presentations at the COP 21 Agreements (2015) Climate Summit indicate that human adaptation of agricultural production systems and supply chains is unlikely to overcome this problem in the face of increasing global population and changing climate, even with the most optimistic emissions scenarios. Lanternfishes which dominate 
the fish community, have attracted attention as a potentially harvestable resource since the 1970's (Gjøsæter and Kawaguchi, 1980; FAO, 1997, 1998, 2001). Some species are considered suitable for human consumption, but mostly the aim has been to supply the fishmeal market. The global biomass of this resource is very large, but just how large is uncertain, due in part to the poor sampling efficiencies of survey gears and partly to the low acoustic target strengths at the sonar frequencies needed to penetrate deep into the ocean interior (Koslow et al., 1997; Kaartvedt et al., 2008; Heino et al., 2011; Davison et al., 2015). Hence, past and current estimates of the biomass of mesopelagic fish could be assumed to be an underestimate of that available. Early estimates of mesopelagic fish biomass were around 1 billion tons (Gjøsæter and Kawaguchi, 1980), with one species Benthosema pterotum suggested to be one of the most dominant vertebrate species on earth (Karuppasamy et al., 2007). Recent acoustic observations have suggested that this is a gross underestimate and that the true figure may be 10 billion tons (Irigoien et al., 2014). Furthermore, at present there are no global estimates of the mesopelagic invertebrate community biomass (also suitable for meal production) though certain fractions have been intensively surveyed and assessed, in particular the Southern Ocean krill for which there is a well established fishery (Constable et al., 2000). Although, there is an increase in the economic interest around mesopelagic resources, the biomass and yield potential and feasibility of exploitation has yet to be assessed.

What is the potential for contributing to human nutrition? Considering a human population on the order of 7.5 billion people this equates to 1.3 metric tons of mesopelagic fish biomass per human on the planet. Putting the estimate of Irigoien et al. (2014) into a food provision context, first we assume that harvested mesopelagic fish biomass is converted to food for human consumption via fish meal. Assuming that fish meal was the only source of raw material for aquaculture feed, and employing the conversion factors of Naylor et al. (2009; i.e., raw material input: aquaculture output of circa 4.0), global aquaculture production in 2014 of 67 million tons (FAO, 2014) would require a harvested mesopelagic fish biomass of 268 million tons. This estimate represents circa 2.7 percent of the most recent global estimate of mesopelagic fish. In reality, vegetable protein is contributing an increasing fraction of aquaculture feed material, though there remains a need for wild-harvesting of essential fatty acids. As an academic exercise if we assume that $50 \%$ of the existing biomass ( 5 billion tons) could be sustainably extracted and converted to food for human consumption via use in the aquaculture industry without overfishing the community then, following Naylor et al. (2009), 5 billion tons of mesopelagic biomass could result in the production of circa 1.25 billion tons of food for human consumption. Given a human population approaching 7.5 billion this represents circa $4.6 \mathrm{~kg}$ of fish biomass per person per day at the present population level.

There are some caveats however. From an industry perspective, the Director General of IFFO (the Fish Meal and Fish Oil producers and consumer's organization), Andrew Mallison, has stated "The industry is certainly in need of more raw material - demand exceeds supply and demand is forecasted to continue growing as global aquaculture (and feed) increases. However, these deeper water fish will be more costly to harvest, and there would have to be a good set of science based harvest control rules to satisfy any environmental or ecosystem impact concerns. If the science indicates a potential sustainable fishery with a reasonable yield, there are several IFFO member companies who could look at the economics of fishing effort and return."

\section{NUTRACEUTICALS}

Another key issue in human nutrition and aquaculture is the availability of nutraceuticals. The growth of nutraceutical products is partly based on a demand for "Omega-3" oils as human dietary supplements, and partly on the expanding aquaculture industry which has a requirement for n-3 LCPUFA in feed material which can currently only be met from natural marine oils. Mesopelagic fisheries targeting nutraceuticalrich species to meet these demands are a new and emerging concept, convergent with the theme of Blue Growth. In the North Atlantic the prime example of an already operational commercial marine nutraceutical venture is "Calanus Oil," which is extracted from the copepod Calanus finmarchicus, harvested in the coastal waters of the Norwegian Sea (http://calanus.no/ en/products/), and marketed in various forms as being rich in omega-3 fatty acids. Lanternfishes are recognized as being high in fatty acids (e.g., Lea et al., 2002). For example, recently, three species (Diaphus watasei, Diaphus suborbitalis and Benthosema pterotum) from the NW Pacific haven been analyzed and found to have high levels of 20:5n-3 and 22:6n-3 fatty acids (icosapentanoic acid (EPA) and docosahexaenoic acid (DHA)). Thus Lanternfishes are a highly attractive source of raw material to support the manufacture of nutraceutical products (Koizumi et al., 2014).

On the Blue Growth nutraceutical potential of mesopelagic fishes, the Director General of IFFO said "The nutraceuticals market does offer better returns for oil than animal feed-it would be interesting to know what loading of PCB's and Dioxin-like PCB's are present as some other North Atlantic fish oil sources require filtering. This incurs a greater cost than South American oils which are 'cleaner' but have to be shipped further to reach EU markets".

Hence, it seems that the Blue Growth potential of Lanternfishes exploitation may be at a cusp between an existing market (for bulk fishmeal) that seems to be barely profitable using exiting harvesting and processing approaches under existing demand conditions and an early-stage emerging market (for nutraceuticals) that could be profitable in the future (Koizumi et al., 2014).

\section{CLIMATE REGULATION}

As is clearly outlined at the COP 21 meeting in Paris in 2015, "Parties should take action to conserve and enhance, as appropriate, sinks and reservoirs of greenhouse gases 
in order to do so an improved knowledge base for the assessment, monitoring and evaluation of the dynamics of carbon sequestration and thus climate regulation is necessary". The mesopelagic region of the ocean, and the community that inhabits it, plays a significant role in the global carbon cycle. The concentration of atmospheric carbon dioxide would be $\sim 50 \%$ higher without the biological carbon pump (BCP) fixing inorganic carbon through photosynthesis by phytoplankton in the surface waters and "exporting" it to depth in the ocean (Parekh et al., 2006). In the North Atlantic alone the BCP exports 0.5-2.7 GtC/year from the surface to depth (Sanders et al., 2014). Models show that atmospheric $\mathrm{CO}_{2}$ concentrations can vary by $\sim 100$ ppm just by using the range of current observations for how deep the organic carbon penetrates before it is demineralized (Kwon et al., 2009). The mesopelagic (100$1000 \mathrm{~m}$ ) is the region directly below the sunlit waters where photosynthesis can occur and the first region to be traversed by any "exported" organic material. The majority of organic carbon is respired in this region (Giering et al., 2014). Its fate is controlled by interactions of the mesopelagic community. Only recently has it proved possible to balance the carbon budget in this region, by taking into account the trophic interactions of the organisms within it (Giering et al., 2014). Our relative lack of understanding of this key region for climate regulation is further highlighted by other recent work (e.g., Jónasdóttir et al., 2015) showing that direct transport of organic carbon by higher trophic level organisms may be a substantial, but hitherto overlooked, pathway for the BCP. The seasonal migration to depth by copepods may result in a downward transport of organic carbon equivalent to that resulting from gravitational sinking in the sub-polar North Atlantic (Jónasdóttir et al., 2015). Vertical migration and excretion/respiration by mesopelagic fish may also be significant. Regional studies have shown that such "active flux" can account for $\sim 10-20 \%$ at depths near the top of the mesopelagic (Davison et al., 2015) but may be as much as $70 \%$ near the bottom (Hudson et al., 2014). Modeling predicts a decrease of $\sim 40 \%$ in downward flux of organic carbon at $1000 \mathrm{~m}$ (the base of the mesopelagic) in the North Atlantic up to 2100 (Yool et al., 2013). However, current global biogeochemical models, such as the one used for that study, do not include the active flux. The role of the mesopelagic community, particularly the higher trophic levels, in exporting carbon to depth in the ocean away from the atmosphere therefore potentially constitutes an order one uncertainty in how the $\mathrm{BCP}$ will respond to regulate climate over the coming century. Climate prediction models provide our primary tool for assessing potential risks posed by future change, the likelihood of such events happening and a testing way of mitigating against them. Modeled scenarios should also investigate the feedback from related pressures on the mesopelagic community: how will the mesopelagic community and the manner in which it processes organic carbon respond to projected changes in temperature, stratification, $\mathrm{pH}$ and oxygen? may there be impacts on climate if we over-exploit the mesopelagic fish stocks? The function of the mesopelagic community in the BCP is therefore a priority for biogeochemical research. Given that the service it provides is global with its activity predominantly carried out in the international waters of the deep ocean, research into and maintenance of the BCP is an international responsibility. For this reason, initiatives like the Galway Statement on Atlantic Ocean Co-operation (2014), and activities that it has already generated, such as the International Planning Workshop for a North Atlantic-Arctic Science Cooperation (Benway et al, 2014), will be key in delivering the thorough investigation of the mesopelagic community's role in regulating climate that is needed.

\section{BIODIVERSITY}

The participating Nations at COP 21 Agreements (2015) noted the "importance of ensuring the integrity of all ecosystems, including oceans, and the protection of biodiversity." Thus, Nations at COP 21 highlighted the need for improving our knowledge of the drivers of biodiversity and ecosystems, conservation restoration and sustainable management of the ecosystems, species and genetic diversity.

There is, however, a major lack of knowledge of the global composition and distribution of mesopelagic diversity, which is under-sampled and sparse in data (Figure 1). An additional problem is that we know very little about the function of mesopelagic biodiversity in the oceanic ecosystems and as providers of critical ecosystem services (Robison, 2009). Potentially important ecosystem services are supported by a largely unknown deep pelagic biodiversity and interactions within the system (Tittensor et al., 2010; Webb et al., 2010), which includes multiple components from microbes to marine megafauna interacting with mesopelagic fish and invertebrates. The ocean's deep interior remains an unexplored frontier. The regular discovery of new clades in this deep pelagic zone, which is estimated to hold a million of undescribed species, is subjected to the development of undersea technology providing unprecedented access, new capabilities, and new perspectives (Robison, 2009). Present research on mesopelagic biodiversity is scarce thus a large gap in our understanding of the global distribution of overall mesopelagic diversity exists. Moreover, the biological adaptations of the organisms to the high stability of the mesopelagic environment make this ecosystem very vulnerable to pressures such as global fisheries and climate change.

This lack of knowledge impedes implementation of international agreements such as: (i) UN Resolution 61/1054 to conserve Vulnerable Marine Ecosystems; (ii) Aichi targets, related to the sustainable management of marine exploitation (applying ecosystem based approaches, avoiding adverse impacts on threatened species and vulnerable ecosystems and ensuring that the impacts of fisheries on stocks, species and ecosystems are within safe ecological limits); (iii) the Convention on Biological Diversity (2009), to identify ecologically or biologically sensitive areas; and (iv) the development of indicators required to assess the environmental status of marine ecosystems under different national and international legislation (i.e., Oceans Act, in US and Canada; Marine Strategy Framework Directive, in Europe; Regional Seas Conventions, worldwide; etc.). 


\section{CONCLUSIONS AND SUGGESTIONS}

The potential negative impacts of anthropogenic activities and climate change on marine ecosystems and human health must be addressed in a full realization of Blue Growth strategy of the mesopelagic. Exploitation of this community is a delicate problem in terms of the consequences for the ecosystem and its services. To tackle the global challenge of securing access to strategic but vulnerable food resources while coping with climate change risks, we need targeted innovation and sustainable development strategies that aim at preserving critical ecosystem services. This includes our oceans as providers, as claimed by the Intergovernmental Platform on Biodiversity and Ecosystem Services (IPBES http://www.ipbes.net). Hence, there is a need to improve resource management (through an ecosystem approach) and governance, to preserve them and to unlock their potential for the sustainable production of new products and industrial applications. To achieve this in relation to the mesopelagic community and its services we need knowledge on

(i) Population vital rates (e.g., recruitment, natural mortality and the effects of abiotic and biotic stressors on growth and survival) with respect to latitude and environmental conditions as the basis for stock assessments and population dynamics modeling to predict the sustainability of harvest rates.

(ii) Stock assessments to address fisheries policy. In the absence of a fishery, there are no existing data on which to base a conventional stock assessment, so we must use other methods relying on survey data and measurements of growth, maturity and natural mortality rates to generate assessments and forecasts of yields under different harvesting rates.

(iii) The links between oceanographic regimes and mesopelagic biomass and biodiversity (species, traits, population genetics and habitats) thus enabling the prediction of species

\section{REFERENCES}

Benway, H. M., Hofmann, E., and St. John, M. A. (2014). Building international research partnerships in the North Atlantic-Arctic region. EOS 95, 317. doi: 10.1002/2014EO350007

Branch, T. A., Jensen, O. P., Ricard, D., Ye, Y., and Hilborn, R. (2011). Contrasting global trends in marine fishery status obtained from catches and from stock assessments. Conserv. Biol. 25, 777-786. doi: 10.1111/j.1523-1739.2011.0 1687.x

Brophy, J. T., Murphy, S., and Rogan, E. (2009). The Diet and Feeding Ecology of the Short-Beaked Common Dolphin (Delphinus delphis) in the Northeast Atlantic. IWC Scientific Committee Document SC/61/SM 14. Cambridge: International Whaling Committee.

Constable, A. J., de la Mare, W. K., Agnew, D. J., Everson, I., and Miller, D. (2000). Managing fisheries to conserve the Antarctic marine ecosystem: practical implementation of the Convention on the Conservation of Antarctic Marine Living Resources (CCAMLR). ICES J. Mar. Sci. 57, 778-791. doi: 10.1006/jmsc. 2000.0725

COP 21 Agreements (2015). POLICY: https://www.wfp.org/climate-change/ climate-policy/cop-21; FOOD SECURITY: http://www.globalfood.cam. ac.uk/news/world-food-programme-at-the-paris-climate-conference; BIODIVERSITY: http://unfccc.int/resource/docs/2015/cop21/eng/l09r01. pdf) dynamics relative to oceanographic regimes which will be impacted as their environment alters under climate change.

(iv) The role of the community in the food web, in particular the dependence of top predators on mesopelagic prey and thus their influence on fisheries and ecotourism.

(v) The role of individual species and the community in the sequestration of green house gases.

Clearly the potential benefits of harvesting the mesopelagic community is immense, however the consequences of mismanagement, unlike for most fish stocks, have global ramifications. Prior to exploitation a scientifically based ecosystem approach to exploitation is needed in particular focusing on the ecosystem and climate controls on the populations in order to avoid an overexploited state as is observed in many marine fish stocks (e.g., Worm et al., 2009; Branch et al., 2011). In this article, we have outlined the issues that need to be considered and the research that needs to be attended to prior to embarking on a Blue growth exploitation strategy in the mesopelagic zone of the oceans.

\section{AUTHOR CONTRIBUTIONS}

All authors listed, have made substantial, direct and intellectual contribution to the work, and approved it for publication.

\section{FUNDING}

All authors were funded by their affiliated agencies.

\section{ACKNOWLEDGMENTS}

We would like to thank Drs. Webjørn Melle and Thor Klevjer from the Norwegian Institute for Marine Research for making the echograms and photographs presented in Figures 1, 2 available to the authors and the home institutes of the authors for providing the funding necessary to generate this article.

Davison, P. C., Checkley, D. M. Jr., Koslow, J. A., and Barlow, J. (2013). Carbon export mediated by mesopelagic fishes in the northeast Pacific Ocean. Progr. Oceanogr. 116, 14-30. doi: 10.1016/j.pocean.2013.05.013

Davison, P. C., Koslow, J. A., and Kloser, J. (2015). Acoustic biomass estimation of mesopelagic fish: backscattering from individuals, populations, and communities. ICES J. Mar. Sci. 72, 1413-1424. doi: 10.1093/icesjms/ fsv, 023

FAO, I. (1997). Review of the State of World Fishery Resources: Marine Fisheries. Lanternfishes: a Potential Fishery in the Northern Arabian Sea? Rome: FAO. FAO Fisheries Circular No. 920 FIRM/C.920

FAO, I. (1998). Trial Fishing for Lantern Fishes (Myctophids) in the Gulf of Oman (1998-1990). Rome: FAO. FAO Fisheries Circular No. 935 FIRM/C.935.

FAO, I. (2001). Report of the Trilateral Workshop on Lanternfish in the Gulf of Oman, Muscat, Oman, 7-9 May 2001. Muscat: FAO. FAO Fisheries Report No. 665 FIIT/R.665.

FAO, I. (2014) State of World Fisheries and Aquaculture 2014. Rome: Food and Agriculture Organization.

Feagans-Bartow, J., and Sutton, T. (2014) Ecology of the oceanic rim: pelagic eels as key ecosystem components. Mar. Ecol. Prog. Ser. 502, 257-266. doi: $10.3354 /$ meps 10707

Galway Statement on Atlantic Ocean Co-operation (2014). Available online at; http://ec.europa.eu/research/index.cfm?pg=newsalertandyear=2015andna $=$ na-160415-1 
Giering, S. L. C., Sanders, R., Lampitt, R. S., Anderson, T. R., Tamburini, C., Boutrif, M., et al. (2014). Reconciliation of the carbon budget in the ocean's twilight zone. Nature 507, 480-483. doi: 10.1038/nature 13123

Gjøsæter, J., and Kawaguchi, K. (1980). A Review of the World Resources of Mesopelagic Fish. Food and Agriculture Org.

Hays, G. (2003). A review of the adaptive significance and ecosystem consequences of zooplankton diel vertical migrations. Hydrobiologia 503, 163-170. doi: 10.1023/B:HYDR.0000008476.23617.b0

Heino, M., Porteiro, F. M., Sutton,; T. T., Falkenhaug, T., Godø, O. R., and Piatkowski, U. (2011). Catchability of pelagic trawls for sampling deepliving nekton in the mid-North Atlantic. ICES J. Mar. Sci. 68, 377-389. doi: 10.1093/icesjms/fsq089

Hidaka, K., Kawaguchi, K., Murakami, M., and Takahashi, M. (2001). Downward transport of organic carbon by diel migratory micronekton in the western equatorial Pacific: its quantitative and qualitative importance. Deep Sea Res.1 Oceanogr. Res. Papers 48, 1923-1939. doi: 10.1016/S0967-0637(01)00 003-6

Hudson, J. M., Steinberg, D. K., Sutton, T. T., Graves, J. E., and Latour, R. J. (2014). Myctophid feeding ecology and carbon transport along the northern Mid-Atlantic Ridge. Deep Sea Res. I. 93, 104-116 doi: 10.1016/j.dsr.2014.0 7.002

Irigoien, X., Klevjer, T. A., Røstad, A.:, Martinez, U., Boyra, G., Acuña, J. L., et al. (2014). Large mesopelagic fishes biomass and trophic efficiency in the open ocean. Nat. Communicat. 5, 3271. doi: 10.1038/ncomms4271

Jónasdóttir, S. H., Visser, A. W., Richardson, K., and Heath, M. R. (2015). Seasonal copepod lipid pump promotes carbon sequestration in the deep North Atlantic. Proc. Natl. Acad. Sci. U.S.A. 112, 12122-12126. doi: 10.1073/pnas.15121 10112

Kaartvedt., S., Torgersen, T., Klevjer, T. A., Røstad, A., and Devine, J. A. (2008). Behavior of individual mesopelagic fish in acoustic scattering layers of Norwegian fjords. Mar. Ecol. Progr. Ser. 360, 201-209. doi: 10.3354/meps07364

Karuppasamy, P. K., Balachandran, K., George, S., Balu, S., Persis, V., and Menon, N. G. (2007). A check list of fishes collected by IKMT from the DSL survey in the Indian EEZ of Arabian Sea. J. Indian Hydro. 9, 311-316.

Koizumi, K., Huratsuka, S., and Saiti, H. (2014). Lipid and fatty acids of three edible Myctophids, Diaphus watasei, Daipus suborbitalis, and Benthosema pterotum: high levels of icosapentaenoic and docosahexaenoic acids. J. Oleo Sci. 63, 461-470. doi: 10.5650/jos.ess13224

Korneliussen, R. J., Ona, E., Eliassen, I., Heggelund, Y., Patel, R., Godø, O. R., et al. (2006). "The large scale survey system - LSSS," in Proceedings of the 29th Scandinavian Symposium on Physical Acoustics (Ustaoset), 29.

Koslow, J. A., Kloser, R. J., and Williams, A. (1997). Pelagic biomass and community structure over the mid-continental slope off southeastern Australia based upon acoustic and midwater trawl sampling. Mar. Ecol. Progr. Ser. 146, 21-35. doi: 10.3354/meps146021

Kwon, E. W., Primeau, F., and Sarmiento, J. L. (2009). The impact of remineralization depth on the air-sea carbon balance. Nat. Géosci. 2, 630-635. doi: $10.1038 /$ ngeo612

Lea, M. A., Nichols, P. D., and Wilson, G. (2002). Fatty acid composition of lipidrich myctophids and mackerel icefish (Champsocephalus gunnari) - Southern Ocean food-web implications. Polar Biol. 25, 843-854. doi: 10.1007/s00300002-0428-1
MacLennan, D. N., Fernandes, P. G., and Dalen, J. (2002). A consistent approach to definitions and symbols in fisheries acoustics. ICES J. Marine Sci., 59, 365-369. doi: 10.1006/jmsc.2001.1158

Melle, W. (2013). Cruise report Cruise no. 2013107. Bergen: IMR.

Naylor, R. L., Hardy, R. W., Bureau, D. P., Chiu, A., Elliott, M., Farrell, A., et al. (2009). Feeding aquaculture in an era of finite resources. Proc. Natl. Acad. Sci. 106, 15103-15110. doi: 10.1073/pnas.0905235106

Parekh, P., Dutkiewicz, S., Follows, M. J., and Ito, T. (2006). Atmospheric carbon dioxide in a less dusty world. Geophys. Res. Lett. 33, L03610. doi: 10.1029/2005GL025098

Paxton, J. R. (1979). Nominal genera and species of lantern fishes (Family Myctophidae). Contrib. Sci., Nat. Hist. Mus. LA. Cty. 332, 1-28.

Potier, M., Marsac, F., Cherel, Y., Lucas, V., Sabatie, R., Maury, O., et al. (2007). Forage fauna in the diet of three large pelagic fishes (lancetfish, swordfish and yellowfin tuna) in the western equatorial. Indian Ocean Fisher. Res. 83, 60-72. doi: 10.1016/j.fishres.2006.08.020

Robison, B. H. (2009). Conservation of deep pelagic biodiversity. Conserv. Biol. 23, 847-858. doi: 10.1111/j.1523-1739.2009.01219.x

Sanders, R., Henson, S. A., Koski, M., De La Rocha, C. L., Painter, S. C., Poulton, A. J., et al. (2014). The biological carbon pump in the North Atlantic. Progr. Oceanogr. 129, 200-218. doi: 10.1016/j.pocean.2014.05.005

Tittensor, D. P., Mora, C., Jetz, W., Lotze, H. K., Ricard, D., Vanden Berghe, E., et al. (2010). Global patterns and predictors of marine biodiversity across taxa. Nature 466, 1098-1102. doi: 10.1038/nature09329

Valinassab, T., Pierce, G. J., and Johannesson, K. (2007). Lantern fish (Benthosema pterotum) resources as a target for commercial exploitation in the Oman Sea. J. Appl. Ichthyol. 23, 573-577. doi: 10.1111/j.1439-0426.2007.01034.x

van Haren, H., and Compton, T. J. (2013). Diel Vertical Migration in Deep Sea Plankton Is Finely Tuned to Latitudinal and Seasonal Day Length. PLoS ONE 8:e64435. doi: 10.1371/journal.pone.0064435

Webb, T. J., Vanden Berghe, E., and O’Dor, R. K. (2010). Biodiversity's big wet secret: The global distribution of marine biological records reveals chronic under-exploration of the deep pelagic ocean. PLOS ONE 5:e10223. doi: 10.1371/journal.pone. 0010223

Worm, B., Hilborn, R., Baum, J. K., Branch, T. A., Collie, J. S., Costello, C., et al. (2009). Rebuilding Global Fisheries. Science 325, 578-585. doi: $10.1126 /$ science. 1173146

Yool, A., Popova, E. E., Coward, A. C., Bernie, D., and Anderson, T. R. (2013). Climate change and ocean acidification impacts on lower trophic levels and the export of organic carbon to the deep ocean. Biogeosciences 10, 5831-5854. doi: 10.5194/bg-10-5831-2013

Conflict of Interest Statement: The authors declare that the research was conducted in the absence of any commercial or financial relationships that could be construed as a potential conflict of interest.

Copyright (๑) 2016 St. John, Borja, Chust, Heath, Grigorov, Mariani, Martin and Santos. This is an open-access article distributed under the terms of the Creative Commons Attribution License (CC BY). The use, distribution or reproduction in other forums is permitted, provided the original author(s) or licensor are credited and that the original publication in this journal is cited, in accordance with accepted academic practice. No use, distribution or reproduction is permitted which does not comply with these terms. 